\title{
Modeling Election Problem by a Stochastic Differential Equation
}

\author{
Nguyen Thanh Trung1,2 \\ ${ }^{1}$ Faculty of Fundamental Science, Military Academy of Logistics, Hanoi, Vietnam \\ ${ }^{2}$ Faculty of Mathematics, Mechanics and Informatics, VNU University of Science, Hanoi, Vietnam \\ Email: nguyenthanhtrung.hvhc@gmail.com
}

How to cite this paper: Trung, N.T. (2018) Modeling Election Problem by a Stochastic Differential Equation. American Journal of Operations Research, 8, 441-447. https://doi.org/10.4236/ajor.2018.86024

Received: August 31, 2018

Accepted: October 27, 2018

Published: October 30, 2018

Copyright $\odot 2018$ by author and Scientific Research Publishing Inc. This work is licensed under the Creative Commons Attribution International License (CC BY 4.0).

http://creativecommons.org/licenses/by/4.0/

\section{(c) (i) Open Access}

\begin{abstract}
The proportion of the favorable among voters to a nominee might change over times and depend on different factors for example: talent, reputation, party and even name order on election. The unobservable factors which might have minor impacts on the approval rate are modelized by random elements. The approval rate is initially described by the differential equation and then by the random differential equation including the above unobservable factors. We figure out the formula of the solution for the stochastic differential equation and simulate these solutions to identify the changes of the approval rate over time.
\end{abstract}

\section{Keywords}

Election, Stochastic Differential Equation, Ito's Formula

\section{The Model}

In democratic countries, the people will elect the president of their country. Presidential candidates (or parliamentarians) need to campaign to get as much voter support as possible. Therefore, studying the fluctuations of voter support for a candidate is very important. Studying the rules of change in favor rates helps the candidate get the right campaign to win. In this article, we modeled the rate of support for a candidate by a random process and examined its movement over time.

The rate of support for a candidate depends on a number of factors, such as candidate's party, election standpoint, personal prestige, world political situation and even order of applicants. Small factors, however, also affect the election results for random errors (see [1]). 
Considering the election problem (presidential election) in which $N$ is population of a specific country, $n(t)$ is the number of voters of a nominee A at time $t$, we let $E$ is the efficiency of the election campaign of $\mathrm{A}$, and $M$ is the spillover effects of his voters to neutral voters or opposing party voters. Then the change of $n(t)$ over time is given by the differential equation:

$$
\frac{\mathrm{d} n(t)}{\mathrm{d} t}=E(N-n(t))+M n(t)(N-n(t))
$$

Let $x(t)=\frac{n(t)}{N} \in[0 ; 1]$ we obtain the differential equation:

$$
\frac{\mathrm{d} x(t)}{\mathrm{d} t}=E(1-x(t))+M N x(t)(1-x(t))=E(1-x(t))+b x(t)(1-x(t))
$$

where $b=M \cdot N$.

Since the efficiency of the campaign contains random elements, we are able to decompose $E$ into two parts: fixed non-random part so-called "a" and random part so-called “ $\sigma a \mathrm{~d} W(t)$ ”. And therefore, the differential Equation (1.2) becomes the stochastic differential equation:

$$
\mathrm{d} x(t)=[a(1-x(t))+b x(t)(1-x(t))] \mathrm{d} t+\sigma a(1-x(t)) \mathrm{d} W(t)
$$

\section{Solution of the Stochastic Differential Equation}

Consider the stochastic differential Equation (1.3)

$$
\mathrm{d} x(t)=[a(1-x(t))+b x(t)(1-x(t))] \mathrm{d} t+\sigma a(1-x(t)) \mathrm{d} W(t)
$$

Let $1-x(t)=X(t)$ we have $-\mathrm{d} x(t)=\mathrm{d} X(t)$ and therefore

$$
\mathrm{d} X(t)=-X(t)[a+b(1-X(t))] \mathrm{d} t+\sigma a X(t) \mathrm{d} W(t)
$$

or

$$
\mathrm{d} X(t)=\left[b X^{2}(t)-(a+b) X(t)\right] \mathrm{d} t-\sigma a X(t) \mathrm{d} W(t)
$$

We now solve the following equation

$$
\mathrm{d} X(t)=\left[\alpha X^{2}(t)+\beta X(t)\right] \mathrm{d} t+\lambda X(t) \mathrm{d} W(t)
$$

where $\alpha, \beta$ and $\lambda$ are parameters of the process $X(t)$.

Let $Y(t)=X^{-1}(t)=\frac{1}{X(t)}$.

By Ito formula ([2]) we have:

$$
\begin{aligned}
\mathrm{d} Y(t) & =-\frac{1}{X^{2}(t)} \mathrm{d} X(t)+\frac{1}{2} \frac{2}{X^{3}(t)} \lambda^{2} X^{2}(t) \mathrm{d} t \\
& =-\frac{1}{X^{2}(t)}\left[\left(\alpha X^{2}(t)+\beta X(t)\right) \mathrm{d} t+\lambda X(t) \mathrm{d} W(t)\right]+\frac{\lambda^{2}}{X(t)} \mathrm{d} t \\
& =-\left(\alpha+\frac{\beta}{X(t)}\right) \mathrm{d} t-\frac{\lambda}{X(t)} \mathrm{d} W(t)+\frac{\lambda^{2}}{X(t)} \mathrm{d} t \\
& =\left(\frac{\lambda^{2}-\beta}{X(t)}-\alpha\right) \mathrm{d} t-\frac{\lambda}{X(t)} \mathrm{d} W(t)
\end{aligned}
$$


So process $Y(t)$ satisfied the following equation

$$
\mathrm{d} Y(t)=\left(\left(\lambda^{2}-\beta\right) Y(t)-\alpha\right) \mathrm{d} t-\lambda Y(t) \mathrm{d} W(t)
$$

The equation given by (2.3) is a linear stochastic differential equation and it can be solved by following lemma.

Lemma 1. The solution of the following stochastic differential equation

$$
\mathrm{d} Y(t)=\left(a_{1} Y(t)+c_{1}\right) \mathrm{d} t+\left(b_{1} Y(t)+d_{1}\right) \mathrm{d} W(t)
$$

has the form

$$
Y(t)=\phi(t)\left[Y(0)+\left(c_{1}-b_{1} d_{1}\right) \int_{0}^{t} \frac{\mathrm{d} s}{\phi(s)}+d_{1} \int_{0}^{t} \frac{\mathrm{d} W(s)}{\phi(s)}\right]
$$

where

$$
\phi(t)=\exp \left\{\left(a_{1}-\frac{b_{1}^{2}}{2}\right) t+b_{1} W(t)\right\} .
$$

Proof.

Assume that $\phi(t)$ the stochastic process, which is satisfied the following equation

$$
\mathrm{d} \phi(t)=a_{1} \phi(t) \mathrm{d} t+b_{1} \phi(t) \mathrm{d} W(t)
$$

and therefore process $\phi(t)$ has the form ( see [3] and [4])

$$
\phi(t)=\exp \left\{\left(a_{1}-\frac{b_{1}^{2}}{2}\right) t+b_{1} W(t)\right\}
$$

Let $Z(t)$ be the process defined by $Z(t)=\frac{Y(t)}{\phi(t)}$. Applying the Ito's formula we have

$$
\begin{aligned}
\mathrm{d} Z(t)= & \frac{1}{\phi(t)} \mathrm{d} Y(t)-\frac{1}{\phi^{2}(t)} Y(t) \mathrm{d} \phi(t) \\
& -\frac{1}{2} \frac{2}{\phi^{2}(t)} \mathrm{d} Y(t) \mathrm{d} \phi(t)+\frac{1}{2} \frac{2 Y(t)}{\phi^{3}(t)} \mathrm{d} \phi(t) \mathrm{d} \phi(t) \\
= & \frac{1}{\phi(t)} \mathrm{d} Y(t)-\frac{1}{\phi^{2}(t)} Y(t)\left[a_{1} \phi(t) \mathrm{d} t+b_{1} \phi(t) \mathrm{d} W(t)\right] \\
& -\frac{1}{\phi^{2}(t)}\left[\left(a_{1} Y(t)+c_{1}\right) \mathrm{d} t+\left(b_{1} Y(t)+d_{1}\right) \mathrm{d} W(t)\right] \\
& \times\left[a_{1} \phi(t) \mathrm{d} t+b_{1} \phi(t) \mathrm{d} W(t)\right]+\frac{Y(t)}{\phi^{3}(t)} \mathrm{d} \phi(t) \mathrm{d} \phi(t)
\end{aligned}
$$

And reduce thif formula we have

$$
\begin{aligned}
\mathrm{d} Z(t)= & \frac{1}{\phi(t)} \mathrm{d} Y(t)-\frac{a_{1} Y(t)}{\phi(t)} \mathrm{d} t-\frac{b_{1} Y(t)}{\phi(t)} \mathrm{d} W(t) \\
& -\frac{1}{\phi(t)}\left[0+0+0+\left(b_{1}^{2} Y(t)+b_{1} d_{1}\right) \mathrm{d} t\right]+\frac{Y(t)}{\phi(t)} b_{1}^{2} \mathrm{~d} t
\end{aligned}
$$


Because (2.4) we obtain

$$
\begin{aligned}
\mathrm{d} Z(t)= & \frac{\left(\left(a_{1} Y(t)+c_{1}\right) \mathrm{d} t+\left(b_{1} Y(t)+d_{1}\right) \mathrm{d} W(t)\right)}{\phi(t)}-\frac{a_{1} Y(t)}{\phi(t)} \mathrm{d} t \\
& -\frac{b_{1} Y(t)}{\phi(t)} \mathrm{d} W(t)-\frac{\left(b_{1}^{2} Y(t)+b_{1} d_{1}\right)}{\phi(t)} \mathrm{d} t+\frac{b_{1}^{2} Y(t)}{\phi(t)} \mathrm{d} t \\
= & \frac{d_{1}}{\phi(t)} \mathrm{d} W(t)+\frac{\left(c_{1}-b_{1} d_{1}\right)}{\phi(t)} \mathrm{d} t
\end{aligned}
$$

Finally, Integrate two side of Equation (2.4a) we have the form of $Z(t)$

$$
Z(t)=Z(0)+\left(c_{1}-b_{1} d_{1}\right) \int_{0}^{t} \frac{\mathrm{d} s}{\phi(s)}+d_{1} \int_{0}^{t} \frac{\mathrm{d} W(s)}{\phi(s)}
$$

where $Z(0)=\frac{Y(0)}{\phi(0)}=Y(0)$ and the solution of $(2.4)$ is

$$
Y(t)=\phi(t)\left[Y(0)+\left(c_{1}-b_{1} d_{1}\right) \int_{0}^{t} \frac{\mathrm{d} s}{\phi(s)}+d_{1} \int_{0}^{t} \frac{\mathrm{d} W(s)}{\phi(s)}\right]
$$

Corollary 1. The solution of (2.3) has the form

$$
Y(t)=\phi(t)\left[Y(0)-\alpha \int_{0}^{t} \frac{\mathrm{d} s}{\phi(s)}\right]
$$

where

$$
\phi(t)=\exp \left\{\left(\frac{\lambda^{2}}{2}-\beta\right) t-\lambda W(t)\right\} .
$$

Proof.

Replace $a_{1}$ in (2.2) by $\lambda^{2}-\beta ; c_{1}$ by $-\alpha, b_{1}$ by $-\lambda$ and $d_{1}=0$ we obtain (2.5)

Corollary 2. The solution of (2.2) has the form

$$
X(t)=\phi^{-1}(t)\left[\frac{1}{X(0)}-\alpha \int_{0}^{t} \frac{\mathrm{d} s}{\phi(s)}\right]^{-1}
$$

where

$$
\phi(t)=\exp \left\{\left(\frac{\lambda^{2}}{2}-\beta\right) t-\lambda W(t)\right\} .
$$

Proof.

Replace $Y(t)$ in (2.5) by $\frac{1}{X(t)}$ we obtain (2.6).

Theorem 1. The solution of (2.1) has the form

$$
X(t)=\phi^{-1}(t)\left[\frac{1}{X(0)}-b \int_{0}^{t} \frac{\mathrm{d} s}{\phi(s)}\right]^{-1}
$$


where

$$
\phi(t)=\exp \left\{\left(\frac{\sigma^{2} a^{2}}{2}+a+b\right) t+\sigma a W(t)\right\} .
$$

\section{Proof.}

It follows from Corollary 2.

\section{Simulation}

Here are simulations of support rate for a candidate in a number of different scenarios. Assume that the candidate initially receives $50 \%$ of the voters and with the different scenarios of the effectiveness of the campaign, how will the support rate change?

In Figure 1 the initial voter turnout was 0.5 , under the influence of the declining early support vote, but then increased and approached randomly.

In Figure 2 the initial voter turnout was 0.3 , the efficiency of the media was 0.5 , the efficiency of word of mouth was -0.6 . We saw the initial support increase but eventually dropped below 0.2 .

In Figure 3 the voter turnout was 0.5 , the efficiency of the media was -0.3 , the effectiveness of word of mouth was 0.6 , the support was initially reduced but eventually increased to 0.6 .

In Figure 4 the voter turnout was 0.5 , the efficiency of the media was -0.3 , the efficiency of word-of-mouth was -0.6 . The initial support margin increased slightly then decreased and then decreased to 0 .

These scenarios show the effectiveness of the campaign, including communication and word of mouth. If one campaign (communication and word of mouth) is ineffective, it leads to failure. In today's technology, word of mouth can be far more effective than before because of the emergence of social networks. The US presidential election of 2016, for example, shows that although Donald Trump was battered by media coverage, he won election through word of mouth through social networking.

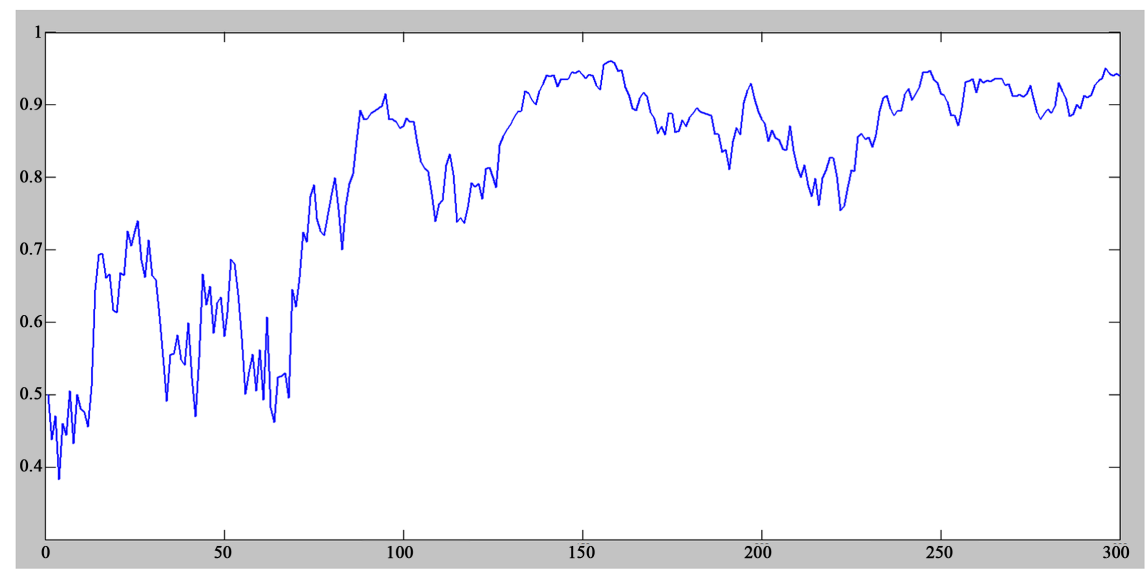

Figure 1. The simulation of $x(t)$ with $a=0.5 ; b=0.2$ and $\sigma=0.3$. 


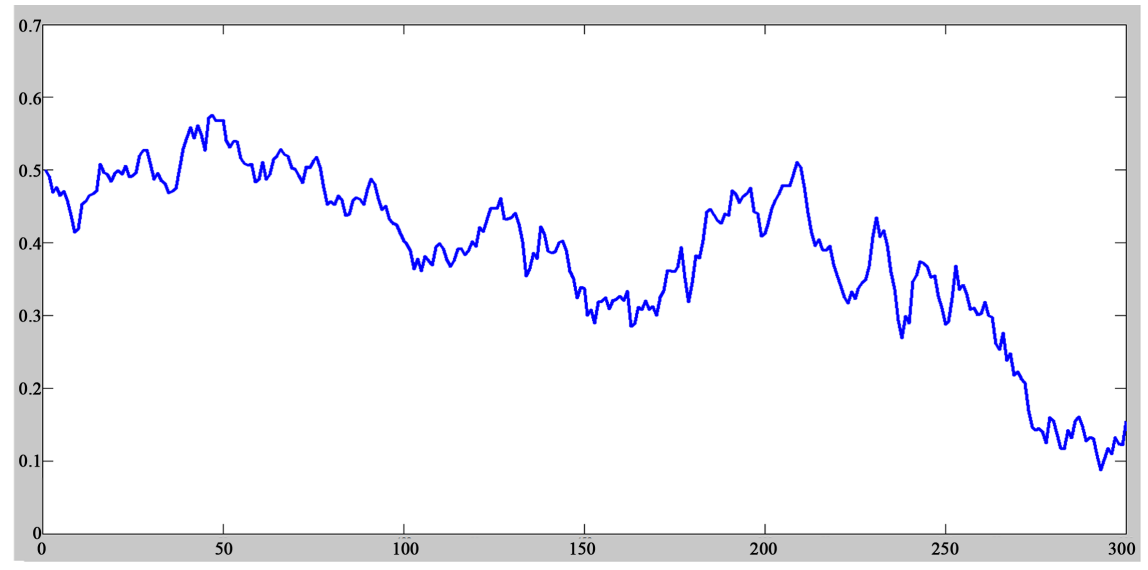

Figure 2. The simulation of $x(t)$ with $a=0.3 ; b=-0.6$ and $\sigma=0.3$.

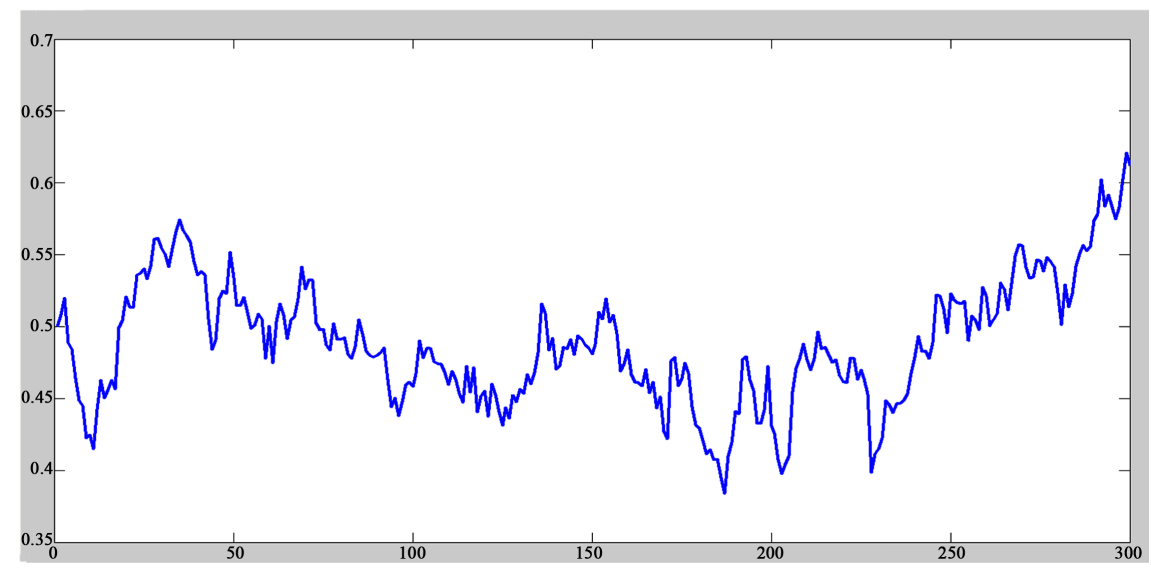

Figure 3. The simulation of $x(t)$ with $a=-0.3 ; b=0.6$ and $\sigma=0.3$.

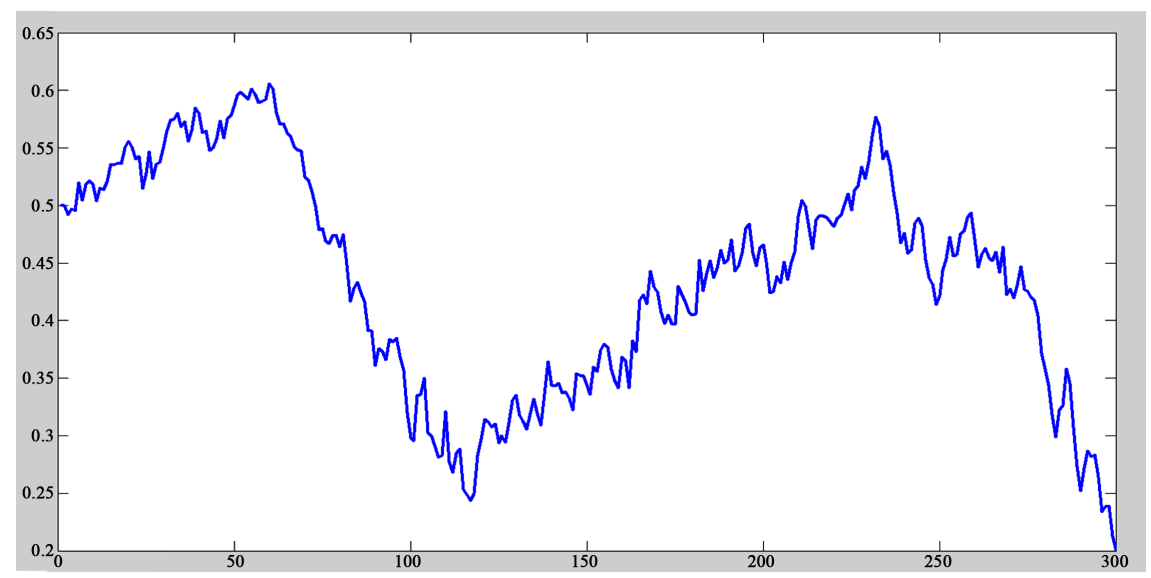

Figure 4. The simulation of $x(t)$ with $a=-0.3 ; b=-0.6$ and $\sigma=0.1$.

\section{Conclusion}

In this paper, we modeled the voter support for a candidate in an election by a random differential equation, solving and simulating them. In further studies we will consider the properties of the stochastic differential equation and use it in 
the optimal stopping problem for the campaign and compare the effectiveness of media campaigns and word of mouth on election results.

\section{Conflicts of Interest}

The author declares no conflicts of interest regarding the publication of this paper.

\section{References}

[1] Chen, E., Simonovits, G., Krosnick, J.A. and Pasek, J. (2014) The Impact of Candidate Name Order on Election Outcomes in North Dakota. Electoral Studies, 35, 115-122. https://doi.org/10.1016/j.electstud.2014.04.018

[2] Ksendal, B. (2003) Stochastic Differential Equations: An Introduction with Applications. Vol. XXVII, Springer, Berlin, 379 p. https://doi.org/10.1007/978-3-642-14394-6

[3] Arnold, L. (1974) Stochastic Differential Equations: Theory and Applications. Wiley, Hoboken, New Jersey.

[4] Malliaris, A.G. (1983) Ito's Calculus in Financial Decision making. SIAM Review, 25, 481-496. https://doi.org/10.1137/1025121 